\title{
Biofilm Thickness Influences Biodiversity in Nitrifying MBBRs-Implications on Micropollutant Removal
}

Torresi, Elena; Fowler, Jane; Polesel, Fabio; Bester, Kai; Andersen, Henrik Rasmus; Smets, Barth F.; Plósz, Benedek G.; Christensson, Magnus

\section{Published in:}

Environmental Science and Technology

Link to article, DOI:

10.1021/acs.est.6b02007

Publication date:

2016

Document Version

Peer reviewed version

Link back to DTU Orbit

Citation (APA):

Torresi, E., Fowler, J., Polesel, F., Bester, K., Andersen, H. R., Smets, B. F., Plósz, B. G., \& Christensson, M. (2016). Biofilm Thickness Influences Biodiversity in Nitrifying MBBRs-Implications on Micropollutant Removal. Environmental Science and Technology, 50(17), 9279-9288. https://doi.org/10.1021/acs.est.6b02007

\section{General rights}

Copyright and moral rights for the publications made accessible in the public portal are retained by the authors and/or other copyright owners and it is a condition of accessing publications that users recognise and abide by the legal requirements associated with these rights.

- Users may download and print one copy of any publication from the public portal for the purpose of private study or research.

- You may not further distribute the material or use it for any profit-making activity or commercial gain

- You may freely distribute the URL identifying the publication in the public portal 
1 Biofilm thickness influences biodiversity in nitrifying MBBRs

2

3

4

5

6

\title{
- Implications on micropollutant removal
}

\author{
Torresi, E. ${ }^{1,2, *}$, Fowler, S.J. ${ }^{1}$, Polesel, F. ${ }^{1}$, Bester, K. ${ }^{3}$, Andersen, H.R. ${ }^{1}$, Smets, B.F. ${ }^{1}$, Plósz, B.G ${ }^{1, *}$, \\ Christensson, M. ${ }^{2}$. \\ ${ }^{1}$ Department of Environmental Engineering, Technical University of Denmark, Bygningstorvet B115, 2800 Kgs. \\ Lyngby, Denmark \\ ${ }^{2}$ Veolia Water Technologies AB - AnoxKaldnes, Klosterängsvägen 11A, SE-226 47 Lund, Sweden \\ ${ }^{3}$ Department of Environmental Science, Aarhus University, Frederiksborgvej 399, 4000 Roskilde, Denmark \\ * Corresponding authors: \\ Email: elto@env.dtu.dk; Phone: +45 45251474 \\ beep@env.dtu.dk; Phone: +45 45251694
}




\section{Abstract}

In biofilm systems for wastewater treatment (e.g., moving bed biofilms reactors-MBBRs) biofilm thickness is typically not under direct control. Nevertheless, biofilm thickness is likely to have a profound effect on the microbial diversity and activity, as a result of diffusion limitation and thus substrate penetration in the biofilm.

In this study, we investigated the impact of biofilm thickness on nitrification and on the removal of more than 20 organic micropollutants in laboratory-scale nitrifying MBBRs. We used novel carriers (Z-carriers - AnoxKaldnes ${ }^{\mathrm{TM}}$ ) that allowed controlling biofilm thickness at 50, 200, 300, 400, and $500 \mu \mathrm{m}$. The impact of biofilm thickness on microbial community was assessed via 16S rRNA gene amplicon sequencing and ammonia monooxygenase (amoA) abundance quantification through quantitative PCR (qPCR). Results from batch experiments and microbial analysis showed that: (i) the thickest biofilm $(500 \mu \mathrm{m})$ presented the highest specific biotransformation rate constants $\left(\mathrm{k}_{\text {bio }}, \mathrm{L}\right.$ $\mathrm{g}^{-1} \mathrm{~d}^{-1}$ ) for 14 out of 22 micropollutants; (ii) biofilm thickness positively associated with biodiversity, which was suggested as the main factor for the observed enhancement of $\mathrm{k}_{\text {bio }}$; (iii) the thinnest biofilm $(50 \mu \mathrm{m})$ exhibited the highest nitrification rate $\left(\mathrm{gN} \mathrm{d}^{-1} \mathrm{~g}^{-1}\right)$, amoA gene abundance and $\mathrm{k}_{\text {bio }}$ values for some of the most recalcitrant micropollutants (i.e., diclofenac and targeted sulfonamides). Although thin biofilms favored nitrification activity and the removal of some micropollutants, treatment systems based on thicker biofilms should be considered to enhance the elimination of a broad spectrum of micropollutants. 


\section{Introduction}

The presence of micropollutants in the effluents of municipal wastewater treatment plants (WWTPs) is well documented ${ }^{1,2}$ and has received increased attention due to the potential threat that they pose to environmental recipients ${ }^{3}$. Optimization of biological wastewater treatment technologies has been explored to improve removal of micropollutants in WWTPs ${ }^{4}$ and to minimize the use of advanced tertiary treatment processes. Laboratory and full-scale studies have previously demonstrated enhanced micropollutant removal under nitrifying conditions ${ }^{5-9}$, which was associated with non-specific cometabolic activity of the ammonia monooxygenase gene (amoA) by ammonia oxidizing bacteria $(\mathrm{AOB})^{7,8,10}$. On the other hand, the enrichment of nitrifying bacteria is generally linked to a longer solid retention time (SRT) compared to heterotrophic bacteria and a positive association between SRT and micropollutant removal was observed in a number of studies ${ }^{11-17}$. Increased biotransformation potential at longer SRT was hypothesized to be induced by an enrichment of slow growing bacteria and by the increased diversity of "microbial specialists" able to biotransform the recalcitrant chemical structure possessed by many micropollutants ${ }^{17}$.

Over the past two decades, research has shown the importance of biodiversity in biological systems ${ }^{19-22}$, and microbial communities with higher richness (the number of species in a community) were found to have higher functionality and stability than microbial communities with lower richness ${ }^{19-22}$. However, biodiversity is a complex concept which includes species richness and evenness (the relative abundance of the species) ${ }^{23}$. While most studies focus on microbial richness, Wittebolle et al. ${ }^{23}$ demonstrated that highly uneven communities (dominated by one or few species) can be less resistant to environmental stress than more even communities. Johnson et al. ${ }^{18}$ further showed that both richness and evenness are positively associated with the removal of some micropollutants in full scale wastewater treatment.

Based on these observations, biofilm systems exhibiting longer SRT (due to enhanced physical retention) and potentially higher biodiversity than conventional activated sludge (CAS) can represent an option to enhance micropollutant removal. Among biofilm systems, moving bed biofilm reactors (MBBRs) seem to be a promising alternative compared to CAS for the elimination of recalcitrant micropollutants, e.g. diclofenac and X-ray contrast media ${ }^{24-26}$.

MBBRs, in which biofilm is grown on specifically designed plastic carriers ${ }^{27}$, are usually operated without direct control of biofilm thickness. However, biofilm thickness can potentially impact biofilm structure and activity. The diffusive transport of substrates, in particular oxygen, from the bulk liquid into the biofilm is the major rate-limiting process in $\mathrm{MBBR}^{28,29}$, thereby creating 
substrate gradients through the biofilm ${ }^{30}$. Increasing biofilm thickness thus results in greater concentration gradients and stratification of metabolic processes throughout the biofilm, likely leading to a more heterogeneous and biodiverse biofilm. However, it is presently unclear how biofilm thickness influences biodiversity and functionality (e.g., micropollutant removal) in biofilm systems, partly due to a lack of technology enabling controlled biofilm thickness.

Therefore, the objectives of the present study were: (i) to investigate the impact of biofilm thickness on nitrification and on the removal of 22 micropollutants in laboratory-scale nitrifying MBBRs by using novel designed carriers (Z-carriers - AnoxKaldnes ${ }^{\mathrm{TM}}$ ), which allowed the development of biofilms of five different thicknesses $(50,200,300,400$ and $500 \mu \mathrm{m}$ ); (ii) to assess how biofilm thickness influence the diversity of microbial communities in terms of richness and evenness; (iii) to evaluate relationships between biofilm activity (i.e., nitrification), biodiversity and micropollutant biotransformation. Overall, this study aims at optimizing the efficiency of biofilm systems towards micropollutant removal by discriminating between the effects of using thin vs thicker biofilms during operation of biofilm based technologies.

\section{Material and methods}

\section{Description of the Z-carriers and controlled biofilm thickness.}

To obtain biofilms of different thicknesses, newly designed carriers from AnoxKaldnes ${ }^{\mathrm{TM}}$ (Zcarriers) were used (Figure S1 in Supporting Information, SI). The Z-carriers are made of polyethylene and, unlike the conventional MBBR carriers, have a saddle shaped grid covered surface, which allows the biofilm to grow on the outside of the carrier rather than in an inside void, as in e.g., the K1-type carrier ${ }^{29}$. As the carriers continuously scrape against each other during reactor operation, the height of the grid wall corresponds to the maximum biofilm thickness.

Five different Z-carriers (named Z50, Z200, Z300, Z400 and Z500) were used in the experiment, with the numbers indicating the grid wall height (equal to the controlled biofilm thickness) in $\mu \mathrm{m}$. Except for the grid wall height, the Z-carriers Z200, Z300, Z400 and Z500 are identical in design, and thus the exposed biofilm area is expected to be the same. Notably, the Z50 type carriers differ slightly from the other Z-carriers by having a flat shape and 10\% lower surface area (Table S1). Although determining exact biofilm thickness requires detailed measurements, the design of the Zcarriers enables a fairly precise control of the biofilm thickness solely by its design ${ }^{29}$. Further details on the Z-carriers used in this study can be found in Table S1. 


\section{MBBRs configuration.}

\section{Continuous-flow operation.}

The laboratory-scale experiment was conducted in two parallel aerobic MBBRs continuously operated using Z-carriers. Reactor 1 (R1) had a working volume of 3 L, containing 200 carriers of each type (Z200, Z300, Z400, Z500) with a total exposed surface area of $1.02 \mathrm{~m}^{2}$ (Table S1). Reactor 2 (R2) had a volume of $1.5 \mathrm{~L}$, containing 293 Z50 carriers with a total exposed surface area of $0.33 \mathrm{~m}^{2}$. To enable differentiation between the 5 types of Z-carriers, they were produced in different colors. The enrichment of nitrifying biofilm was performed by feeding the reactors (in continuous-flow mode) with effluent wastewater from a local municipal treatment plant (Källby, Lund, Sweden), spiked with ammonium $\left(50 \mathrm{mg} \mathrm{L}^{-1}\right.$ of $\mathrm{NH}_{4}-\mathrm{N}$ as $\left.\mathrm{NH}_{4} \mathrm{Cl}\right)$ and phosphorus $\left(0.5 \mathrm{mg} \mathrm{L}^{-}\right.$ ${ }^{1}$ of $\mathrm{PO}_{4}-\mathrm{P}$ as $\mathrm{KH}_{2} \mathrm{PO}_{4}$ ). For details about the start-up of the MBBR systems, readers should refer to S1 in SI. Hydraulic residence time (HRT) after the start-up procedure was kept equal to 2 hours for both reactors. Temperature was set at $20{ }^{\circ} \mathrm{C}$ using a thermostat bath and $\mathrm{pH}$ was kept at $7 \pm 0.5$ by using $400 \mathrm{mg} \mathrm{L}^{-1}$ as $\mathrm{CaCO}_{3}$ of alkalinity (in the form of $\left.\mathrm{NaHCO}_{3}\right)$ and sodium hydroxide $\left(20 \mathrm{mg} \mathrm{L}^{-}\right.$ ${ }^{1}$ ). Aeration intensity was set so that an average dissolved oxygen concentration (DO) of $4.5 \pm 0.5$ $\mathrm{mg} \mathrm{L}^{-1}$ could be maintained in both biofilm reactors. Thus, $\mathrm{R} 1$ and $\mathrm{R} 2$ reactors were fed using the same influent quality and with identical operational conditions (i.e., HRT, DO, temperature). MBBR R2 was initiated 45 days after the start-up of MBBR R1 as Z50 carriers were produced at a later time. In order to maintain the same HRT and filling ratio as R1, the volume of R2 is different. Samples were analyzed for bulk chemicals $\left(\mathrm{NH}_{4}-\mathrm{N}, \mathrm{NO}_{3}-\mathrm{N}, \mathrm{NO}_{2}-\mathrm{N}, \mathrm{COD}\right.$, alkalinity, $\left.\mathrm{PO}_{4}{ }^{3-}\right)$ semiweekly. R1 and R2 were operated for approximately 300 days under continuous-flow operation (Figure S2).

\section{Batch operation.}

Two different batch experiments to assess micropollutant removal were performed (Figure S2). Batch experiment 1 was performed with five different types of Z-carriers after reaching stable ammonia removal (at day 168 for $\mathrm{R} 1$ and at day 123 for $\mathrm{R} 2$ ) and using the exact same feed as in continuous operation (batch-feed 1) without micropollutant spiking. Batch experiment 2 was done using Z50, Z200 and Z500 at day 275 and 230 of operation for R1 and R2 respectively. Batch experiments were done using batch-feed 1 with additional spiking of 23 micropollutants with an initial concentration of $1 \mu \mathrm{g} \mathrm{L}^{-1}$ for most of the compounds and of $15 \mu \mathrm{g} \mathrm{L}^{-1}$ for the X-ray contrast media as they are usually found at higher concentrations in the effluent wastewater ${ }^{31}$. Micropollutants were added from a stock solution $\left(40 \mathrm{mg} \mathrm{L}^{-1}\right)$ containing the chemical compounds 
dissolved in methanol. To minimize the increase of organic substrates in the nitrifying system, micropollutant stock solutions were first spiked into an empty glass beaker and methanol was allowed to evaporate in the fumehood for approximately 1 hour. Prior batch experiments, the continuous-flow systems R1 and R2 were disconnected, the five types of Z-carriers (200 each) were manually separated through color recognition and placed in separated batch glass reactors (operating volume of $1 \mathrm{~L}$ ). Samples $(\mathrm{n}=12)$ for micropollutant analysis and nitrogen species were taken at regular intervals (Table S2) from the reactors over $24 \mathrm{~h}$. To maintain the same biomass concentration over the duration of the experiment, three carriers were withdrawn from the reactors each time a sample $(14 \mathrm{~mL})$ was taken for analysis. $\mathrm{pH}$ and $\mathrm{DO}$ were continuously monitored and manually adjusted to 7.5 (using $\mathrm{pH}$ buffer) and $4.5 \mathrm{mg} \mathrm{L}^{-1}$, respectively, during the experiment. An additional reactor was used as a control experiment to assess abiotic degradation of micropollutants. The experiment was divided into two parts as previously proposed ${ }^{25}$, (i) without plastic carriers and using only filtered (with $0.2 \mu \mathrm{m}$ pore size Munktell MG/A glass fiber filter) effluent wastewater to asses abiotic degradation and sorption onto glass walls; and (ii) with new carriers added to filtered effluent wastewater to investigate sorption onto plastic carriers (Table S2). Batch sorption experiments were also performed with biomass inhibition by using allythiourea $\left(10 \mathrm{mg} \mathrm{L}^{-1}\right)$ and sodium azide $\left(0.5 \mathrm{mg} \mathrm{L}^{-1}\right)$ to estimate the sorption coefficient $\mathrm{K}_{\mathrm{d}}$. A description of the experimental method and $\mathrm{K}_{\mathrm{d}}$ values are presented in $\mathrm{S} 2$.

\section{Chemicals.}

Twenty-three environmentally relevant micropollutants were selected for this study, which included some of the most frequently detected pharmaceuticals in wastewater effluents ${ }^{31}$. Furthermore, to investigate possible trends among groups of pharmaceuticals, the targeted pharmaceuticals were grouped in six categories according to their use. The micropollutants included: (i) four beta-blocker pharmaceuticals atenolol (ATN), metoprolol (MET), propranolol (PRO) and sotalol (SOT); (ii) five X-ray contrast media diatrizoic acid (DIA), iohexol (IOH), iopamidol (IOP) iopromide (IOPR), iomeprol (IOM); (iii) sulfonamide antibiotics sulfadiazine (SDZ), sulfamethizole (SMZ) and sulfamethoxazole (SMX), one combination product, trimethoprim (TMP), and one metabolite acetyl-sulfadiazine (AcSDZ); (iv) three anti-inflammatory pharmaceuticals phenazone (PHE), diclofenac (DCF), ibuprofen (IBU); (v) three anti-epileptic/anti-depressants carbamazepine (CBZ), venlafaxine (VFX) and citalopram (CIT); (vi) three macrolide antibiotics, erythromycin (ERY), 
clarithromycin (CLA) and roxithromycin (ROX). For information regarding CAS numbers and chemical suppliers, the reader should refer to Escolà Casas et al. ${ }^{24}$.

\section{Analytical methods.}

Samples taken for analysis of conventional pollutants $\left(\mathrm{NH}_{4}-\mathrm{N}, \mathrm{NO}_{3}-\mathrm{N}, \mathrm{NO}_{2}-\mathrm{N}, \mathrm{COD}\right.$, alkalinity, $\mathrm{PO}_{4}{ }^{3-}$ ) were filtered through $0.45 \mu \mathrm{m}$ glass fiber filters (Sartorius, Göttingen, Germany). Hach Lange kits (LCK 303, LCK 339, LCK 341 and LCK 342) were used and analyzed using a spectrophotometer (Hach Lange DR2800).

The attached biomass concentrations were calculated from the difference in weight of 3 dried carriers $\left(105{ }^{\circ} \mathrm{C}\right.$ for $>24 \mathrm{~h}$ ) before and after biofilm removal (using $2 \mathrm{M} \mathrm{H}_{2} \mathrm{SO}_{4}$ with subsequent brushing), as previously considered ${ }^{24,32,33}$. These results were used to normalize the nitrification and biotransformation rate constants. The volatile suspended solids (VSS) measurement, needed to normalize the results from microbial characterization, was conducted by scraping and dissolving the attached biofilm in tap water and measured according to APHA standard methods ${ }^{34}$. Micropollutant concentrations in the liquid phase were analyzed by sampling $4 \mathrm{ml}$ of water sample from each reactor with a glass pipette. Micropollutants were determined successively by direct injection to HPLC-MS/MS as described by Escolà Casas et al. ${ }^{24}$ and as reported in supplementary information (S3). Information regarding HPLC-MS/MS and mass spectrometry data, limit of detection (LOD) and quantification (LOQ) of compounds is shown in Escolà Casas et al. ${ }^{24}$.

\section{Nitrification.}

Nitrification rates were calculated as (i) ammonia uptake rate per gram of attached biomass $\mathrm{r}_{\mathrm{NH} 4 \_\mathrm{B}}$ $\left(\mathrm{gN}_{-} \mathrm{NH}_{4}{ }^{+} \mathrm{d}^{-1} \mathrm{~g}^{-1}\right)$ and (ii) ammonia uptake rate per carrier surface area $\mathrm{r}_{\mathrm{NH} 4 \_} \mathrm{s}\left(\mathrm{gN}-\mathrm{NH}_{4}{ }^{+} \mathrm{d}^{-1} \mathrm{~m}^{-2}\right)$. Nitrification rates were derived through linear regression of $\mathrm{NH}_{4}{ }^{+}-\mathrm{N}$ concentration during batch experiments under non-limiting ammonia conditions $\left(\mathrm{NH}_{4}{ }^{+}>20 \mathrm{mg} \mathrm{L}^{-1}\right)$. To estimate kinetic paramters a 1-D two-step nitrification biofilm model, including growth and decay of ammonia (AOB) and nitrite oxidizing bacteria (NOB), was implemented in Aquasim $2.1 \mathrm{~d}^{35}$. Maximum specific growth rates for $\mathrm{AOB}$ and $\mathrm{NOB}\left(\mu_{\max , \mathrm{AOB}}\right.$ and $\left.\mu_{\max , \mathrm{NOB}}\right)$, and affinity constants for ammonium and nitrite $\left(\mathrm{K}_{\mathrm{NH} 4 \text { _AOB }}\right.$ and $\left.\mathrm{K}_{\mathrm{NO} 2 \text { _NOB }}\right)$ were estimated by considering values of yield coefficient $\left(\mathrm{Y}_{\mathrm{AOB}}, \mathrm{Y}_{\mathrm{NOB}}\right)$ derived from literature ${ }^{36}$. The parameters were estimated by calibrating the model to measured concentrations of $\mathrm{NH}_{4}{ }^{+}-\mathrm{N}, \mathrm{NO}_{2}{ }^{-}-\mathrm{N}$ and $\mathrm{NO}_{3}{ }^{-}-\mathrm{N}$ during batch experiments, 
attached biomass concentration and estimated AOB and NOB fractions from microbial analysis (qPCR) to define initial conditions. Details of the model are presented in S4.

\section{Micropollutant biotransformation.}

Model structure to describe micropollutant removal in batch 1 and 2, were identified using the Activated Sludge Model framework for Xenobiotics (ASM-X) ${ }^{16,37,38}$. Accordingly, pseudo firstorder biotransformation rate constants $\mathrm{k}_{\mathrm{bio}}\left(\mathrm{L} \mathrm{gTSS}^{-1} \mathrm{~d}^{-1}\right)$, biomass normalized, were calculated according to Eq.1:

$\frac{d C_{L I}}{d t}=-\frac{k_{b i o}}{\left(1+K_{d} X\right)} C_{L I} X$

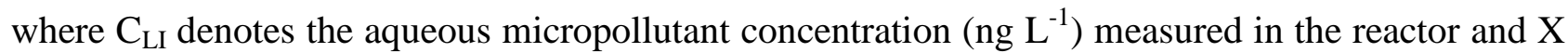
the attached biomass concentration on Z-carriers $\left(\mathrm{g} \mathrm{L}^{-1}\right)$. Sorption onto biofilm can influence the availability of the aqueous micropollutant for biodegradation ${ }^{34}$ and sorption coefficient $\mathrm{K}_{\mathrm{d}}\left(\mathrm{L} \mathrm{g}^{-1}\right)$ was included in Eq. 1, by assuming instantaneous sorption equilibrium ${ }^{39,40}$. Biotransformation rate constants $\mathrm{k}_{\text {bio }}$ were estimated from the measured data using least-square optimization without weighting with GraphPad Prism 5.0.

A retransformation-biotransformation model was developed and retransformation rates kec $\left(\mathrm{L} \mathrm{g}^{-1} \mathrm{~d}^{-}\right.$

${ }^{1}$ ) were estimated using the secant method embedded in Aquasim $2.1 \mathrm{~d}^{35}$ according to Eq. 2:

$\frac{d C_{L I}}{d t}=-\frac{k_{b i o}}{\left(1+K_{d} X\right)} C_{L I} X+k_{D e c} C_{C J} X$

where $\mathrm{C}_{\mathrm{CJ}}$ accounts for the fraction of micropollutant present as e.g., conjugate undergoing retransformation to the parent compound. Further details of biokinetics estimation are presented in S5. As the estimation of micropollutants biokinetics considers the total amount of attached biomass, we note that the estimated $\mathrm{k}_{\text {bio }}$ lumps biotransformation by nitrifying and heterotrophic bacteria, which were subsequently estimated using qPCR. The effect of diffusion into biofilm on the removal of micropollutants from bulk aqueous phase was lumped in the biotransformation rate constants, as previously considered ${ }^{24-26,40}$.

Biotransformation rate constants normalized to the surface area of the MBBR, $\mathrm{k}_{\mathrm{S}}\left(\mathrm{m}^{-2} \mathrm{~d}^{-1}\right)$ were calculated to compare the performance of the three MBBR batch systems, regardless of biomass concentration. 
Duplicates of biomass samples for each Z-carrier were collected before batch 2 and stored in sterilized Eppendorf tubes at $-20{ }^{\circ} \mathrm{C}$. Biomass was detached using a sterile brush (Gynobrush, Dutscher Scientific, United Kingdom) and tap water, the sample was centrifuged (10000 rpm for 5 minutes), and the supernatant was removed. The collected biomass was subject to DNA extraction using the MP FastDNA ${ }^{\mathrm{TM}}$ SPIN Kit (MP Biomedicals LLC., Solon, USA) following manufacturer's instructions. The concentration and purity of extracted DNA were measured by spectrophotometry (NanoDrop Technologies, Wilmington, DE, USA). Quantitative PCR (qPCR) targeting 16S rRNA and functional genes was carried out according to Pellicer-Nàcher et al. ${ }^{41}$ to estimate the abundance of total bacteria (EUB), ammonia oxidizing bacteria (AOB, based on 16S rRNA-gene and amoA gene), ammonia oxidizing archaea (amoA-gene), and nitrite oxidizing bacteria (NOB, Nitrospira spp. and Nitrobacter spp, based on 16S rRNA- gene). Primers are reported in Table S4.

\section{S rRNA gene amplification, sequencing and bioinformatic analysis.}

PCR amplification and sequencing were performed at the DTU Multi Assay Core Center (Kgs Lyngby, DK). Briefly, DNA was PCR amplified using 16S rRNA bacterial gene primers PRK341F (5'- CCTAYGGGRBGCASCAG-3') and PRK806R (5'-GGACTACNNGGGTATCTAAT-3' ${ }^{42}$ targeting the V3 and V4 region. The thermocycling protocol is reported in S6. PCR products were purified using AMPure XP beads (Beckman-Coulter) prior to index PCR (Nextera XT, Illumina) and sequencing by Illumina MiSeq. Paired-end reads were assembled and low quality sequencing reads were removed using mothur ${ }^{43}$. Taxonomic assignment and calculation of alpha diversity metrics (Shannon, ACE and Chao extrapolated richness) was performed in mothur using the RDP reference taxonomy. To identify the relative fraction of aerobic and anaerobic bacteria, sequences were clustered at the family level and their electron acceptor preference based on literature ${ }^{44,45}$. Additional diversity indices were calculated according to $\mathrm{Hill}^{46}$. Microbial evenness was estimated as $\mathrm{H}_{1} / \mathrm{H}_{0}$ as described in Johnson et $\mathrm{al}^{18}$. 


\section{Statistical analysis.}

The statistical methods used comprise: (i) Pearson correlation analysis (parametric test) to assess possible association between $\mathrm{k}_{\text {bio }}$ of individual micropollutant and biofilm thickness; (iii) one-way analysis of variance (ANOVA) with non-parametric test (Kruskal-Wallis test) to evaluated significance difference between parameters of alpha-diversity measured for the different biofilm thicknesses. The statistical analysis was computed in Prism 5.0. In addition, non-parametric rank correlation and permutation tests were performed (see section S10 for details).

\section{Results and discussion}

\section{Continuous-flow operation of the MBBR systems.}

During the start-up phase, which lasted approximately $80 \mathrm{~d}$ for R1, and $50 \mathrm{~d}$ for R2, the gradual increase of the ammonium loading resulted in a rapid increase of nitrification rate for the two MBBRs (Figure S4). After 88 and $50 \mathrm{~d}$ of operation, R1 and R2 reached an average ammonium removal rate of $1.88 \pm 0.22 \mathrm{gN} \mathrm{d}^{-1} \mathrm{~m}^{-2}$ and $2.38 \pm 0.47 \mathrm{gN} \mathrm{d}^{-1} \mathrm{~m}^{-2}$ respectively, which stabilized to an average value of $2.21 \pm 0.23 \mathrm{gN} \mathrm{d}^{-1} \mathrm{~m}^{-2}$ for the duration of the experiment. Removal of the fraction of biodegradable COD from the effluent wastewater $\left(\sim 10 \mathrm{mg} \mathrm{L}^{-1}\right.$ averaged concentration) was less than $11 \%$ in $\mathrm{R} 1$ and $8 \%$ in $\mathrm{R} 2$, suggesting the presence of active heterotrophic biomass which was subsequently estimated by qPCR (Table S5). Nitrite production was negligible $(<0.1 \mathrm{gN}$ $\mathrm{d}^{-1} \mathrm{~m}^{-2}$ ) in both reactors with the exception of two sampling points where failure in the system resulted in temporary nitrite accumulation with subsequent performance recovery within $5 \mathrm{~d}$. Measurements performed on the Z-carriers at different days of operation revealed increased attached biomass concentration with increased biofilm thickness, with the biomass concentration in Z500 being approximately 4.5- fold higher than in Z50 (Figure S5).

\section{Influence of biofilm thickness on nitrification.}

Two sets of batch experiments (batch 1 and batch 2) were used to assess biokinetics of nitrification and micropollutant removal (Figure S2). Here we present results only from batch 2, whereas results from batch 1 (where no micropollutant spiking was performed) are reported in Figure S7 and S12. 
282 The nitrification rates $\mathrm{r}_{\mathrm{NH} 4 \_\mathrm{B}}\left({\mathrm{gN}-\mathrm{NH}_{4}}^{+} \mathrm{d}^{-1} \mathrm{~g}^{-1}\right)$ obtained from linear regression of ammonium 283 concentration profiles (Figure S6) and normalized by biomass concentration were 3- and 4-fold 284 higher in Z50 compared to Z200 and Z500 respectively (Figure 1 A). Likewise, nitrification rates 285 normalized by surface area $\mathrm{r}_{\mathrm{NH} 4 \_} \mathrm{S}\left(\mathrm{gN}-\mathrm{NH}_{4}{ }^{+} \mathrm{d}^{-1} \mathrm{~m}^{-2}\right)$ were found higher for $\mathrm{Z50}$ compared to the 286 other biofilm thicknesses although with marginal difference. We also observed that an increase of 287 biofilm thickness beyond $200 \mu \mathrm{m}$ did not result in any significant increase in nitrification rates. 288 Similar results were previously found through 1-D biofilm modeling of nitrifying MBBR 289 demonstrating that biofilm thickness over approximately $200 \mu \mathrm{m}$ did not influence effluent 290 ammonium concentrations ${ }^{47}$. Higher nitrification rates for thinner biofilms $(20-30 \mu \mathrm{m})$ has 291 previously been hypothesized to be a result of a more active aerobic upper biofilm layer compared 292 to thicker biofilms where accumulation of less-active biomass occurs in deeper layers ${ }^{48}$. Less 293 diffusion limitation in the thin biofilms could also lead to nitrifying communities with higher 294 functional attributes compared to those in thicker biofilms. To test this hypothesis, we estimated the 295 maximum specific growth rate $\left(\mu_{\max }\right)$ of AOB by defining the initial biomass concentration of the 296 autotrophic bacteria based on the fraction of AOB and NOB estimated by qPCR analysis as 297 described in section S4 and S7. We observed that the estimated specific growth rates $\mu_{\operatorname{maxAOB}}$ 298 followed a trend similar to $\mathbf{r}_{\mathrm{NH}_{4} \mathrm{~B}}$ (Fig 1A), i.e., significantly decreased $\mathbf{r}_{\mathrm{NH} 4 \_\mathrm{B}}$ with increasing 299 biofilm thickness. We also observed higher values of substrate (ammonium) affinity constant $300 \mathrm{~K}_{\mathrm{NH} 4 \_\mathrm{AOB}}$ within Z50 with a decreasing trend over biofilm thickness (Table S6). Values of $\mu_{\operatorname{maxAOB}}$ 301 obtained for the thinnest biofilm (Figure 1A) are slightly higher compared to that estimated for 302 activated sludge ${ }^{49}$ (Table S6). Nevertheless, the estimated specific growth kinetics supports the 303 hypothesis of functional differentiation, in terms of nitrification, with varying biofilm thickness. 304 Previous studies identified a large diversity of nitrifiers ${ }^{50,51}$, and modelling of microbial competition 305 in nitrifying biofilms showed how their spatial distribution can follow $r$ - and $K$ - selection 306 theory ${ }^{49,52,53}$. Accordingly, a vertical distribution of different autotrophic microorganisms was 307 observed where $K$-strategist (with lower substrate affinity constant and maximum growth rate 308 compared to r-strategists) populated all layers of the biofilm equally while r-strategists were only 309 present in the active surface of the biofilm. Accordingly, in our study fast-growing organisms that 310 adapted to high substrates availability (i.e., ammonia), characterized by high $\mu_{\operatorname{maxAOB}}$ and high 311 values of substrate affinity constant $\mathrm{K}_{\mathrm{NH} 4 \_ \text {AOB }}$ (r-strategists) have mainly populated the surface 312 layers of thin biofilms (Z50-Z200) unlike thicker biofilms due to reduced diffusion limitation. 


\section{Micropollutant removal kinetics.}

Most of the investigated chemicals were removed according to first-order kinetics (goodness of fit is presented in Table S7), allowing for the estimation of removal rate $\mathrm{k}_{\mathrm{S}}$ (Figure S19) and biotransformation rate constant $\mathrm{k}_{\text {bio }}$ (Figure 2). However, two compounds (i.e., DCF and SMX) were removed according to different kinetics. DCF exhibited an initial increase of concentration given by the retransformation of its human metabolites such as sulfate and glucuronide conjugates ${ }^{54}$ (possibly present in the effluent wastewater used in the batch experiment) to parent compound (Figure 2). Hence, kinetics of retransformation $\mathrm{k}_{\text {Dec }}$ were estimated along with $\mathrm{k}_{\text {bio }}$ (Table S8), according to Plósz et al. ${ }^{16}$. SMX data showed different process kinetics in batch 1 and 2 (Figure 2; Figure S8). SMX was removed according to first-order kinetics in batch 2 (Figure S10). On the other hand, in batch 1, SMX concentration profiles obtained with the Z500 and Z200 carriers suggest significant cometabolic effects (enhancement by ammonia availability), unlike that obtained with Z50 and all profiles obtained in batch 2. Biotransformation of SMX was previously predicted using a cometabolic kinetic model ${ }^{7,16}$, whereby the primary substrate affects (enhances or competitively inhibits) micropollutants biotransformation.

Ibuprofen was completely removed in the first 15 minutes of the experiment, preventing the estimation of $\mathrm{k}_{\mathrm{bio}}$. Finally, micropollutants removal measured during the control experiment was less than $10 \%$ (Figure S11), indicating that no abiotic removal was observed during batch experiment.

\section{Impact of biofilm thickness on removal of individual micropollutants.}

Biotransformation rates $\mathrm{k}_{\mathrm{bio}}$ were estimated for 22 spiked chemical compounds (Figure 3). We tested the correlation between $\mathrm{k}_{\text {bio }}$ and biofilm thickness by estimating Pearson's coefficients, $r$. Results were classified as (i) positive correlations when $r>0$ and (ii) negative correlation when $r<$ 0. We observed three important outcomes: (i) for 14 over 22 spiked chemical compounds, $\mathrm{k}_{\text {bio }}$ positively correlated with biofilm thickness $\left(\mathrm{r}>0.8\right.$ ), (ii) $\mathrm{k}_{\text {bio }}$ showed low correlation with four compounds $(-0.2 \leq \mathrm{r}<0.2)$, and (iii) for the three sulfonamide antibiotics (SMX, SDZ and SMZ) and DCF, the estimated $\mathrm{k}_{\text {bio }}$ showed negative correlation $(\mathrm{r}=-0.9)$ with biofilm thickness. Pearson's coefficients (r) are reported in Table S9. The results from the rank correlation and permutation tests (Figure S17 and S18) showed that the positive correlation between $\mathrm{k}_{\mathrm{bio}}$ and biofilm thickness found for 14 of 22 spiked micropollutants is significant different $(\mathrm{p}<0.05)$, suggesting a dependence of biotransformation rate constants on biofilm thickness at 95\% confidence level (see section S10). 
346 Compounds with positive correlation.

347 Beta-blockers. Previous studies have shown, with the exception of $\mathrm{ATN}^{5,6}$, moderate 348 biodegradability of beta-blockers in activated sludge (Table S8) and no direct link to ammonia 349 oxidation $^{55,56}$. In our study, removal of ATN, MET, and PRO was higher in the Z500 biofilm, with 350 ATN presenting the highest $\mathrm{k}_{\text {bio }}$ among the beta blockers in agreement with previous studies ${ }^{24,57}$. 351 Significantly higher $\mathrm{k}_{\text {bio }}$ with $\mathrm{Z500}$ were found for ATN and PRO compared to previous 352 observations in activated sludge ${ }^{55}$ and $\mathrm{MBBR}^{24}$. On the other hand, ATN and PRO presented high 353 sorption affinity to biofilm (highest for Z500, Figure S3) possibly indicating underestimation of 354 biotransformation rate constants in previous studies that neglected sorption ${ }^{24}$. SOT was removed to 355 a very low extent and the $\mathrm{k}_{\text {bio }}$ obtained was significantly lower than in previous studies using not 356 enriched nitrifying communities ${ }^{24,55}$. This suggests that the removal of SOT might not be linked to 357 autotrophic activity. Although biotransformation of beta-blockers (with exception of SOT) was 358 enhanced in the nitrifying MBBR in the present study in comparison to activated sludge, their 359 removal seems to be related to the biofilm microbial community and not necessarily to nitrification 360 activity.

Iodinated X-ray contrast media (ICM). While in batch 1 we observed extremely low removal of the 363 iodinated contrast media (IOH, IOM, IOP, IOPR) across all biofilm thicknesses (Figure S7), after approximately 230 days of operation the thick biofilm Z500 had developed the capability to degrade these compounds. On the other hand, less than $2 \%$ of the ICM were removed during either batch experiments by Z50 biofilm. Overall, ICM showed lower removal rate constants compared to other targeted compounds in this study, with $\mathrm{k}_{\text {bio }}$ values comparable to those reported in previous investigations $^{24,26}$. No sorption of ICM was observed in this study (Figure S3). ICM have high polarity and are designed to be resistant to human metabolism ${ }^{58}$. It has been suggested that the slow biotransformation of ICM is due to steric hindrance caused by the iodine atoms which prevent enzyme to access the aromatic rings ${ }^{58}$. The slowest removal of IOP (Table S8), having the greatest steric hindrance, supports this hypothesis. Our results further suggest that increased biofilm thickness is beneficial for the removal of ICM. Biotransformation of ICM occurs mainly via deiodination, a process which includes reductive dehalogenation at low redox potential ${ }^{26,59}$. Higher diffusion limitation of oxygen in the thicker biofilm may have led to a lower redox potential that facilitated dehalogenation of ICM compounds. 
Anti-depressants/ Anti-epileptics. The comparably low $\mathrm{k}_{\mathrm{bio}}$ estimated for the antidepressant VFX is in line with previous studies ${ }^{24,40}$. VFX removal was previously associated with ammonia oxidation activity $^{5}$ but in our study no removal of venlafaxine was observed in Z50 carriers (Figure S10), exhibiting the highest nitrification activity. CIT, which was found to be moderately removed in activated sludge ${ }^{12}$, exhibited $\mathrm{k}_{\text {bio }}$ values for Z500 similar to what reported from another study on aerobic MBBRs ${ }^{24}$.

Antibiotics. The biotransformation rate constants of two macrocyclic (CLA and ERY) antibiotics and TMP showed positive correlation with biofilm thickness. Controversial results have been found for TMP, the removal of which was positively associated with nitrification ${ }^{60}$, as well as with heterotrophic activity ${ }^{24,61}$. Although it is difficult to identify the process involved in TMP removal, our study suggests that microbial species other than nitrifiers could play a role in its biotransformation. Estimated $\mathrm{k}_{\mathrm{bio}}$ for ERY and CLA agrees well with previous studies using activated sludge and $\mathrm{MBBR}^{7,24}$. As observed for beta-blockers, significantly higher sorption of ERY and CLA was observed in Z500 (Figure S3) compared to Z50 and Z200.

\section{Compounds with negative correlation.}

Biotransformation kinetics of DCF, SDZ, SMZ, and SMX were found to be negatively correlated with biofilm thickness, which, in turn, suggests an association of biotransformation processes with nitrification activity (see e.g., $\mu_{\max , \mathrm{AOB}}$ in Figure 1A). Studies on the biotransformation of DCF in activated sludge suggested cometabolic enhancement by growth substrate, with $\mathrm{k}_{\text {bio }}$ obtained in the absence and presence of growth substrate around 0.1 and $1.2 \mathrm{~L} \mathrm{gSS}^{-1} \mathrm{~d}^{-1}$, respectively ${ }^{16}$. The latter value agrees well with $\mathrm{k}_{\mathrm{bio}}$ values for thickest biofilm estimated in this study ${ }^{16}$. On the other hand, $\mathrm{k}_{\text {bio }}$ values obtained for the thinnest biofilm were about four times higher than those in the thickest biofilm, supporting the hypothesis that DCF removal is positively associated with nitrification. Likewise, the removal of SDZ, SMZ and SMX supports the same hypothesis (Figure 2). This is in agreement with a recent study in which SMX removal positively associated with nitrification in synthetic wastewater ${ }^{58}$, while no previous studies have investigated this link for SDZ and SMZ. The main human metabolites of SDZ, AcSDZ ${ }^{63}$, did not to follow the same trend as the parent compound as its biotransformation (via de-acetylation) was significantly enhanced with increasing biofilm thickness. 


\section{Compounds with low correlation.}

The removal kinetics of the antibiotic ROX, the analgesic PHE, the antidepressant CBZ and the Xray contrast media DIA were found to be weakly correlated with biofilm thickness $(-0.2 \leq \mathrm{r}<0.2)$, partly because of the negligible removal measured with Z50 biofilm (Figure S8 and S9). $\mathrm{k}_{\text {bio }}$ values obtained for CBZ agrees well with that obtained with activated sludge ${ }^{16}$. For ROX, $\mathrm{k}_{\text {bio }}$ value obtained for $\mathrm{Z} 200 \quad\left(0.7 \mathrm{~L} \mathrm{~g}^{-1} \mathrm{~d}^{-1}\right)$ was significantly lower than that obtained in activated sludge nitrifying reactors ${ }^{15,60}$. As for DIA $\left(\mathrm{k}_{\text {bio }}<0.1 \mathrm{~L} \mathrm{~g}^{-1} \mathrm{~d}^{-1}\right)$ and PHE $\left(\mathrm{k}_{\mathrm{bio}} \sim 0.6 \mathrm{~L} \mathrm{~g}^{-1} \mathrm{~d}^{-1}\right)$ our results were in line with previous evidence on activated sludge ${ }^{16,39}$ and $\mathrm{MBBR}^{24}$ (Table S8).

\section{Impact of biofilm thickness on community structure.}

To investigate the impact of increasing biofilm thickness on the community structure, we quantified the relative abundance of targeted $\mathrm{AOB}$ and NOB using $16 \mathrm{~S}$ as well as ammonia monoxygenase ( $a m o A)$ functional gene by qPCR (further details are reported in S8). In addition, we calculated total community biodiversity using $16 \mathrm{~S}$ rRNA amplicon sequencing. Overall, the thinner biofilm (Z50) exhibited significantly higher $(\mathrm{p}<0.05)$ AOB (based on $16 \mathrm{~S}$ and $a m o A)$ and $\mathrm{NOB}$ relative abundance per gram of biomass (quantified as volatile suspended solids, VSS) compared with the other biofilm thicknesses (Figure S13 and Fig 1B), in accordance with the higher nitrifying activity found in the thin biofilm. We estimated by qPCR the fraction of heterotrophic bacteria to be between 10 and 53\%, being the lowest in Z50 biofilms (Table S5). In all the biofilms, Archaea amoA were below the detection limit. For all of the carriers, 374970 high quality sequences were recovered by $16 \mathrm{~S}$ rRNA amplicon sequencing. Samples were normalized to 19313 sequences per sample and clustered into an average of 856 observed OTUs at 97\% sequence similarity. Shannon taxonomic diversity and evenness index were significantly lower in Z50 compared to thicker biofilms. (Figure 1C and in Table S10). This suggests that increasing biofilm thickness over $200 \mu \mathrm{m}$ does not substantially increase functionality (as observed for nitrification activity) or biofilm biodiversity. Although ACE and Chao (extrapolated taxonomic) richness metrics were observed to increase somewhat with biofilm thickness, this change was not significant (Figure 1C, Table S10). As biodiversity lumps together both microbial richness and evenness, the significant increase of Shannon index and evenness index $\left(\mathrm{H}_{1} / \mathrm{H}_{0}\right)$ with biofilm thickness, coupled with an insignificant change in species richness, points towards an increase in evenness with thickness (Figure 1D). Finally, we investigated the relative fraction of aerobic and anaerobic bacteria in the different biofilms, observing that more than $65 \%$ of the community of the Z50 biofilm was aerobic and 
aerobic/facultative bacteria, with decreasing fraction over thickness (Figure S15). Overall, this suggested a shift from a more aerobic but less biodiverse microbial community in the Z50 to a less aerobic but more biodiverse and most importantly, more evenly distributed community with increasing biofilm thickness.

\section{Correlations of activity and community structure with micropollutant} biotransformation.

We assessed the correlation of the micropollutant biotransformation rates of each compound - at different biofilm thickness - with nitrification rates $\left(\mathrm{r}_{\mathrm{NH} 4 \_} \mathrm{B}\right)$ and microbial community structure (Figure 4). For all the investigated chemicals, the correlation between $\mathrm{k}_{\mathrm{bio}}$, Shannon and Evenness indices followed a linear model (Figure S16). Conversely, correlations between $\mathrm{k}_{\mathrm{bio}}$, nitrification and amoA abundance were predicted more accurately with a logarithmic model (i.e, with a decelerating shape, Figure S16). A decelerating shape was previously observed to better describe the correlation between biodiversity and micropollutant multifunctionality in a full-scale study on activated sludge ${ }^{18}$.

Pearson correlation analysis (values reported in Table S11-14) indicated that most of the micropollutant biotransformation rate constants that were positively correlated with biofilm thickness $\left(\mathrm{L}_{\mathrm{F}}\right.$ in Figure 4) were also positively associated with Shannon taxonomic diversity (r>0.8) (Figure 4). Hence, the removal of this group of chemicals (mainly beta-blockers, ICM, the antidepressants CIT and VFX and the antibiotics TMP and ERY) could be enhanced by a more even microbial community. In agreement with the findings by Wittebolle et al. ${ }^{23}$, we observed that a microbial community with a more even distribution can maximize its functionality even in nonstressed conditions. Furthermore, for the micropollutants with the lowest $\mathrm{k}_{\mathrm{bio}}\left(<0.4 \mathrm{~L} \mathrm{~g} \mathrm{~g}^{-1}\right.$; SOT, AcSDZ and the ICM IOM), stronger correlations ( $r>0.98$ ) with both Shannon and evenness indices (Table S13 and S14) were shown, suggesting the importance of maximizing biodiversity in biofilms to enhance removal of the most recalcitrant compounds. This finding is supported by previous studies $^{18}$, where strong associations with biodiversity were observed for rare micropollutant biotransformations (e.g. VFX). Likewise, compounds such as SOT, IOM, AcSDZ, VFX and TMP (with biotransformation rate constants positively correlated with biofilm thickness) exhibited negative correlation between $\mathrm{k}_{\mathrm{bio}}$ and $a m o A$ abundance or nitrification rate (Figure 4), indicating that their removal is possibly related to the biodiversity of the heterotrophic and not autotrophic community. 
We further observed a positive association between biotransformation kinetics, nitrification rate $\mathrm{r}_{\mathrm{NH} 4 \_\mathrm{B}}(\mathrm{r}>0.9)$ and $a m o A$ abundance $(\mathrm{r}>0.7)$ for compounds with $\mathrm{k}_{\text {bio }}$ negatively correlated with biofilm thickness (with the exception of SDZ). The relationship between micropollutants removal and $a m o A$ abundance has been previously observed ${ }^{61,64}$, and Nitrosomonas europaea is known to catalyze hydroxylation reactions with aromatic compounds and estrogens ${ }^{65}$. SMX and DCF mainly undergo biotransformation via hydroxylation to hydroxy-N-(5-methyl-1,2-oxazol-3-yl)benzene-1sulfonamide and $4^{\prime}$-hydroxydiclofenac respectively ${ }^{66,67}$, supporting the hypothesis that their biotransformation is linked to the abundance of $a m o A$ gene and nitrification. Furthermore, a recent study observed suppressed SMX removal in a nitrifying SBR when amoA was inhibited by allylthiourea $^{59}$. SDZ and SMZ have very similar chemical structures and biotransformation pathways similar to SMX were predicted by the EAWAG-BBD pathway prediction systems ${ }^{68}$. Although, association with $a m o A$ abundance and nitrification were not previously investigated for SDZ and SMZ, it is likely that hydroxylation is also the primary pathway involved in the removal of these compounds and that higher abundance of amoA could potentially enhanced their removal.

Nonetheless, all the targeted sulfonamides and DCF exhibited stronger correlation to nitrification rate $(\mathrm{r}>0.9)$ compared to $a m o A$ abundance $(\mathrm{r}>0.7)$ (Figure 4$)$. Helbling et al. ${ }^{5}$ observed a strong correlation between $\mathrm{k}_{\mathrm{bio}}$, nitrification rate and archaeal $a m o A$ for a number of micropollutant (i.e., isoproturon, ranitidine and VFX) in activated sludge but inhibition of ammonia monooxygenase activity had little effect on their biotransformation (undergoing mainly via oxidative reactions). Thus, they suggested that other enzymes involved in nitrification besides amoA (e.g., hydroxylamine oxidoreductase) could be responsible for the removal of these compounds.

Overall, the examination of micropollutant biotransformation, nitrification and microbial community structure contributed to understanding the effect of using thin or thick biofilms in biofilm-based technologies. We have shown that by using a thicker biofilm $(500 \mu \mathrm{m})$, which resulted in increased microbial biodiversity, the biotransformation kinetics of more than $60 \%$ of the targeted compounds were maximized. This is also supported by the estimated transformation rates $\mathrm{k}_{\mathrm{S}}$ normalized by biofilm surface area (Figure S19), which in Z500 were higher than or comparable to other biofilm thicknesses for most compounds. In full-scale operation, thicker biofilm $(\sim 500 \mu \mathrm{m})$ could potentially optimize the removal of most of the micropollutants targeted in this study.

On the other hand, we demonstrated that a thin biofilm $(50 \mu \mathrm{m})$ could increase the removal of four of the targeted compounds (SDZ, SMZ, SMX and DCF), which have previously been considered 
505 recalcitrant ${ }^{39}$. It is likely that the removal of these compounds is enhanced by the significantly 506 higher nitrification rate and amoA abundance of a less diffusion limited thin biofilm $(50 \mu \mathrm{m})$.

507 Finally, our results suggest that although thin biofilm $(\sim 50 \mu \mathrm{m})$ can achieve complete nitrification 508 and increase the removal of some key compounds, biofilm technologies based on thicker biofilms 509 could enhance the removal of a major number of micropollutants.

\section{Acknowledgements}

512 This research was supported by MERMAID: an Initial Training Network funded by the People 513 Programme (Marie-Curie Actions) of the European Union's Seventh Framework Programme 514 FP7/2007-2013/ under REA grant agreement n. 607492. The authors thank the technical assistance 515 provided by VA SYD at Källby wastewater treatment plant and Associate Professor Olivier Thas 516 (Ghent University) for the support on the statistical analyses.

\section{Associated content}

519 Supporting Information Available. This information is available free of charge via the Internet at 520 http://pubs.acs.org. The Supporting Information is divided in ten sections containing relevant tables 521 (Table S1-S17) and figures (Figure S1-S19). 


\section{References}

(1) Ternes, T. A. Occurrence of drugs in German sewage treatment plants and rivers. Water Res. 1998, 32 (11), 3245-3260.

(2) Plósz, B. G.; Leknes, H.; Liltved, H.; Thomas, K. V. Diurnal variations in the occurrence and the fate of hormones and antibiotics in activated sludge wastewater treatment in Oslo, Norway. Sci. Total Environ. 2010, 408 (8), 1915-1924.

(3) Reemtsma, T.; Weiss, S.; Mueller, J.; Petrovic, M.; González, S.; Barcelo, D.; Ventura, F.; Knepper, T. P. Polar Pollutants Entry into the Water Cycle by Municipal Wastewater: A European Perspective. Environ. Sci. Technol. 2006, 40 (17), 5451-5458.

(4) Petrie, B.; McAdam, E. J.; Lester, J. N.; Cartmell, E. Assessing potential modifications to the activated sludge process to improve simultaneous removal of a diverse range of micropollutants. Water Res. 2014, 62, 180-192.

(5) Helbling, D. E.; Johnson, D. R.; Honti, M.; Fenner, K. Micropollutant Biotransformation Kinetics Associate with WWTP Process Parameters and Microbial Community Characteristics. 2012, 46, 10579-10588.

(6) Sathyamoorthy, S.; Chandran, K.; Ramsburg, C. A. Biodegradation and cometabolic modeling of selected beta blockers during ammonia oxidation. Environ. Sci. Technol. 2013, 47 (22), 12835-12843.

(7) Fernandez-Fontaina, E.; Carballa, M.; Omil, F.; Lema, J. M. Modelling cometabolic biotransformation of organic micropollutants in nitrifying reactors. Water Res. 2014, 65C, $371-383$.

(8) Tran, N. H.; Urase, T.; Kusakabe, O. The characteristics of enriched nitrifier culture in the degradation of selected pharmaceutically active compounds. J. Hazard. Mater. 2009, 171 (13), 1051-1057.

(9) Forrez, I.; Carballa, M.; Boon, N.; Verstraete, W. Biological removal of 17 $\alpha$-ethinylestradiol (EE2) in an aerated nitrifying fixed bed reactor during ammonium starvation. J. Chem. Technol. Biotechnol. 2009, 84 (1), 119-125.

(10) Dawas-Massalha, A.; Gur-Reznik, S.; Lerman, S.; Sabbah, I.; Dosoretz, C. G. Co-metabolic 
oxidation of pharmaceutical compounds by a nitrifying bacterial enrichment. Bioresour. Technol. 2014, 167, 336-342.

(11) Kreuzinger, N.; Clara, M.; Strenn, B.; Kroiss, H. Relevance of the sludge retention time ( SRT ) as design criteria for wastewater treatment plants for the removal of endocrine disruptors and pharmaceuticals from wastewater. 1998, 50 (5), 149-156.

(12) Suárez, S.; Reif, R.; Lema, J. M.; Omil, F. Mass balance of pharmaceutical and personal care products in a pilot-scale single-sludge system: influence of T, SRT and recirculation ratio. Chemosphere 2012, 89 (2), 164-171.

(13) Maeng, S. K.; Choi, B. G.; Lee, K. T.; Song, K. G. Influences of solid retention time, nitrification and microbial activity on the attenuation of pharmaceuticals and estrogens in membrane bioreactors. Water Res. 2013, 47 (9), 3151-3162.

(14) Radjenović, J.; Petrović, M.; Barceló, D. Fate and distribution of pharmaceuticals in wastewater and sewage sludge of the conventional activated sludge (CAS) and advanced membrane bioreactor (MBR) treatment. Water Res. 2009, 43 (3), 831-841.

(15) Suarez, S.; Lema, J. M.; Omil, F. Removal of Pharmaceutical and Personal Care Products ( PPCPs ) under nitrifying and denitrifying conditions. Water Res. 2010, 44 (10), 3214-3224.

(16) Plósz, B. G.; Langford, K. H.; Thomas, K. V. An activated sludge modeling framework for xenobiotic trace chemicals (ASM-X): assessment of diclofenac and carbamazepine. Biotechnol. Bioeng. 2012, 109 (11), 2757-2769.

(17) Clara, M.; Kreuzinger, N.; Strenn, B.; Gans, O.; Kroiss, H. The solids retention time-a suitable design parameter to evaluate the capacity of wastewater treatment plants to remove micropollutants. Water Res. 2005, 39 (1), 97-106.

(18) Johnson, D. R.; Helbling, D. E.; Lee, T. K.; Park, J.; Fenner, K.; Kohler, H. P. E.; Ackermann, M. Association of biodiversity with the rates of micropollutant biotransformations among full-scale wastewater treatment plant communities. Appl. Environ. Microbiol. 2015, 81 (2), 666-675.

(19) Cardinale, B. J. Biodiversity improves water quality through niche partitioning. Nature 2011, 472 (7341), 86-89.

(20) Cardinale, B. J.; Duffy, J. E.; Gonzalez, A.; Hooper, D. U.; Perrings, C.; Venail, P.; Narwani, 
A.; Mace, G. M.; Tilman, D.; A.Wardle, D. Biodiversity loss and its impact on humanity. Nature 2012, 489 (7415), 326-326.

(21) Emmett Duffy, J. Why biodiversity is important to the functioning of real-world ecosystems. Front. Ecol. Environ. 2009, 7 (8), 437-444.

(22) Naeem, S.; Li, S. Biodiversity enhances ecosystem reliability. Nature 1997, 390 (6659), 507509.

(23) Wittebolle, L.; Marzorati, M.; Clement, L.; Balloi, A.; Daffonchio, D.; Heylen, K.; De Vos, P.; Verstraete, W.; Boon, N. Initial community evenness favours functionality under selective stress. Nature 2009, 458 (7238), 623-626.

(24) Escolà Casas, M. E.; Chhetri, R. K.; Ooi, G.; Hansen, K. M. S.; Litty, K.; Christensson, M.; Kragelund, C.; Andersen, H. R.; Bester, K. Biodegradation of pharmaceuticals in hospital wastewater by staged Moving Bed Biofilm Reactors (MBBR). Water Res. 2015, 83, 293302.

(25) Falås, P.; Baillon-Dhumez, a; Andersen, H. R.; Ledin, A; la Cour Jansen, J. Suspended biofilm carrier and activated sludge removal of acidic pharmaceuticals. Water Res. 2012, 46 (4), 1167-1175.

(26) Hapeshi, E.; Lambrianides, A; Koutsoftas, P.; Kastanos, E.; Michael, C.; Fatta-Kassinos, D. Investigating the fate of iodinated X-ray contrast media iohexol and diatrizoate during microbial degradation in an MBBR system treating urban wastewater. Environ. Sci. Pollut. Res. Int. 2013, 20 (6), 3592-3606.

(27) Ødegaard, H. Innovations in wastewater treatment: - the moving bed biofilm process. Water Sci. Technol. 2006, 53 (9), 17.

(28) Gapes, D. J.; Keller, J. Impact of oxygen mass transfer on nitrification reactions in suspended carrier reactor biofilms. Process Biochem. 2009, 44, 43-53.

(29) Piculell, M.; Welander, P.; Jönsson, K.; Welander, T. Evaluating the Effect of Biofilm Thickness on Nitrification in Moving Bed Biofilm Reactors. 2016, 37 (6), 732-743.

(30) Stewart, P. S.; Franklin, M. J. Physiological heterogeneity in biofilms. Nat Rev Micro 2008, $6(3), 199-210$.

(31) Margot, J.; Rossi, L.; Barry, D. A.; Holliger, C. A review of the fate of micropollutants in 
wastewater treatment plants. Wiley Interdiscip. Rev. Water 2015, 2 (5), 457-487.

(32) Falås, P.; Wick, A.; Castronovo, S.; Habermacher, J.; Ternes, T. A.; Joss, A. Tracing the limits of organic micropollutant removal in biological wastewater treatment. Water Res. 2016, 95, 240-249.

(33) Mazioti, A. a.; Stasinakis, A. S.; Pantazi, Y.; Andersen, H. R. Biodegradation of benzotriazoles and hydroxy-benzothiazole in wastewater by activated sludge and moving bed biofilm reactor systems. Bioresour. Technol. 2015, 192, 627-635.

(34) Clesceri, L. S. Standard methods for the examination of water and wastewater; American Public Health Association, 1989.

(35) Reichert, P. Aquasim - a tool for simulation and data-analysis of aquatic systems. Water Sci. Technol. 1994, 30 (2), 21-30.

(36) Brockmann, D.; Rosenwinkel, K.-H.; Morgenroth, E. Practical identifiability of biokinetic parameters of a model describing two-step nitrification in biofilms. Biotechnol. Bioeng. 2008, 101 (3), 497-514.

(37) Plósz, B. G. Y.; Leknes, H.; Thomas, K. V. Impacts of competitive inhibition, parent compound formation and partitioning behavior on the removal of antibiotics in municipal wastewater treatment. Environ. Sci. Technol. 2010, 44 (2), 734-742.

(38) Plósz, B. G.; Benedetti, L.; Daigger, G. T.; Langford, K. H.; Larsen, H. F.; Monteith, H.; Ort, C.; Seth, R.; Steyer, J.-P.; Vanrolleghem, P. a. Modelling micro-pollutant fate in wastewater collection and treatment systems: status and challenges. Water Sci. Technol. 2013, 67 (1), 115.

(39) Joss, A.; Zabczynski, S.; Göbel, A.; Hoffmann, B.; Löffler, D.; McArdell, C. S.; Ternes, T. a.; Thomsen, A.; Siegrist, H. Biological degradation of pharmaceuticals in municipal wastewater treatment: Proposing a classification scheme. Water Res. 2006, 40 (8), 16861696.

(40) Falås, P.; Longrée, P.; la Cour Jansen, J.; Siegrist, H.; Hollender, J.; Joss, a. Micropollutant removal by attached and suspended growth in a hybrid biofilm-activated sludge process. Water Res. 2013, 47 (13), 4498-4506.

(41) Pellicer-Nàcher, C.; Sun, S.; Lackner, S.; Terada, A.; Schreiber, F.; Zhou, Q.; Smets, B. F. 
Sequential aeration of membrane-aerated biofilm reactors for high-rate autotrophic nitrogen removal: experimental demonstration. Environ. Sci. Technol. 2010, 44 (19), 7628-7634.

(42) Yu, Y.; Lee, C.; Kim, J.; Hwang, S. Group-specific primer and probe sets to detect methanogenic communities using quantitative real-time polymerase chain reaction. Biotechnol. Bioeng. 2005, 89 (6), 670-679.

(43) Schloss, P. D. Introducing mothur: A Computational Toolbox for Describing and Comparing Microbial Communities. Abstr. Gen. Meet. Am. Soc. Microbiol. 2009, 75 (23), 7537-7541.

(44) Krieg, N. R. Bergey's manual of systematic bacteriology. Volume four, The bacteroidetes, spirochaetes, tenericutes (mollicutes), acidobacteria, fibrobacteres, fusobacteria, dictyoglomi, gemmatimonadetes, lentisphaerae, verrucomicrobia, chlamydiae, and planctomycetes; Springer, 2010.

(45) Holt, J. G. Bergey’s manual of systematic bacteriology; Springer, 2001.

(46) Hill, M. Diversity and evenness: a unifying notation and its consequences. Ecology 1973, 54 (2), 427-432.

(47) Boltz, J. P.; Morgenroth, E.; Brockmann, D.; Bott, C.; Gellner, W. J.; Vanrolleghem, P. A. Systematic evaluation of biofilm models for engineering practice: Components and critical assumptions. Water Sci. Technol. 2011, 64 (4), 930-944.

(48) Liu, Y.; Capdeville, B. Dynamics of nitrifying biofilm growth in biological nitrogen remov al process. 1994, 29 (7), 377-380.

(49) Vannecke, T. P. W.; Volcke, E. I. P. Modelling microbial competition in nitrifying biofilm reactors. Biotechnol. Bioeng. 2015, 112 (12), 2550-2561.

(50) Bothe, H.; Jost, G.; Schloter, M.; Ward, B. B.; Witzel, K.-P. Molecular analysis of ammonia oxidation and denitrification in natural environments. FEMS Microbiol. Rev. 2000, 24 (5), 673-690.

(51) Otawa, K.; Asano, R.; Ohba, Y.; Sasaki, T.; Kawamura, E.; Koyama, F.; Nakamura, S.; Nakai, Y. Molecular analysis of ammonia-oxidizing bacteria community in intermittent aeration sequencing batch reactors used for animal wastewater treatment. Environ. Microbiol. 2006, 8 (11), 1985-1996.

(52) A Andrews, J. R-Selection and k-selection and microbial ecology. Adv. Microb. Ecol. 1986, 
9, 99-147.

(53) Lydmark, P.; Lind, M.; Sörensson, F.; Hermansson, M. Vertical distribution of nitrifying populations in bacterial biofilms from a full-scale nitrifying trickling filter. Environ. Microbiol. 2006, 8 (11), 2036-2049.

(54) Stierlin, H.; Faigle, J. W.; Sallmann, A.; Kung, W.; Richter, W. J.; Kriemler, H.-P.; Alt, K. O.; Winkler, T. Biotransformation of diclofenac sodium (Voltaren $\left.{ }^{\circledR}\right)$ in animals and in man. Xenobiotica 1979, 9 (10), 601-610.

(55) Wick, A.; Fink, G.; Joss, A.; Siegrist, H.; Ternes, T. A. Fate of beta blockers and psychoactive drugs in conventional wastewater treatment. Water Res. 2009, 43 (4), 1060-1074.

(56) Maurer, M.; Escher, B. I.; Richle, P.; Schaffner, C.; Alder, a C. Elimination of beta-blockers in sewage treatment plants. Water Res. 2007, 41 (7), 1614-1622.

(57) Nielsen, U.; Hastrup, C.; Klausen, M. M.; Pedersen, B. M.; Kristensen, G. H.; Jansen, J. L. C.; Bak, S. N.; Tuerk, J. Removal of APIs and bacteria from hospital wastewater by MBR plus $\mathrm{O}(3), \mathrm{O}(3)+\mathrm{H}(2) \mathrm{O}(2), \mathrm{PAC}$ or $\mathrm{ClO}(2)$. Water Sci. Technol. 2013, 67 (4), 854-862.

(58) Kormos, J. L.; Schulz, M.; Kohler, H. P. E.; Ternes, T. A. Biotransformation of selected iodinated X-ray contrast media and characterization of microbial transformation pathways. Environ. Sci. Technol. 2010, 44 (13), 4998-5007.

(59) Mohn, W; Tiedje, J.M. Microbial reductive dehalogenation. Microbiol. Rev. 1992, 56 (3), 482-507.

(60) Fernandez-Fontaina, E.; Omil, F.; Lema, J. M.; Carballa, M. Influence of nitrifying conditions on the biodegradation and sorption of emerging micropollutants. Water Res. 2012, 46 (16), 5434-5444.

(61) Khunjar, W. O.; Mackintosh, S. A.; Baik, S.; Aga, D. S.; Love, N. G. Elucidating the Relative Roles of Ammonia Oxidizing and Heterotrophic Bacteria during the Biotransformation of 17 r -Ethinylestradiol and Trimethoprim. 2011, 45 (8) 3605-3612.

(62) Kassotaki, E.; Buttiglieri, G.; Ferrando-Climent, L.; Rodriguez-Roda, I.; Pijuan, M. Enhanced sulfamethoxazole degradation through ammonia oxidizing bacteria co-metabolism and fate of transformation products. Water Res. 2016, 94, 111-119.

(63) Vree, T. B.; de Ven, E. S. van; Verwey-van Wissen, C. P. W. G. M.; Baars, A. M.; Swolfs, 
A.; van Galen, P. M.; Amatdjais-Groenen, H. Isolation, identification and determination of sulfadiazine and its hydroxy metabolites and conjugates from man and Rhesus monkey by high-performance liquid chromatography. J. Chromatogr. B Biomed. Sci. Appl. 1995, 670 (1), 111-123.

(64) Shi, J.; Fujisawa, S.; Nakai, S.; Hosomi, M. Biodegradation of natural and synthetic estrogens by nitrifying activated sludge and ammonia-oxidizing bacterium Nitrosomonas europaea. Water Res. 2004, 38 (9), 2322-2329.

(65) Keener, W. K.; Arp, D. J. Transformations of Aromatic Compounds by Nitrosomonas europaea. 1994, 60 (6), 1914-1920.

(66) Bouju, H.; Nastold, P.; Beck, B.; Hollender, J.; Corvini, P. F. X.; Wintgens, T. Elucidation of biotransformation of diclofenac and 4'hydroxydiclofenac during biological wastewater treatment. J. Hazard. Mater. 2016, 301, 443-452.

(67) Gauthier, H.; Yargeau, V.; Cooper, D. G. Biodegradation of pharmaceuticals by Rhodococcus rhodochrous and Aspergillus niger by co-metabolism. Sci. Total Environ. 2010, 408 (7), 1701-1706.

\section{Web references}

(68) EAWAG-BBD Pathway Prediction System. http://eawag-bbd.ethz.ch/predict/index.html (Accessed February 24, 2016). 2016. 

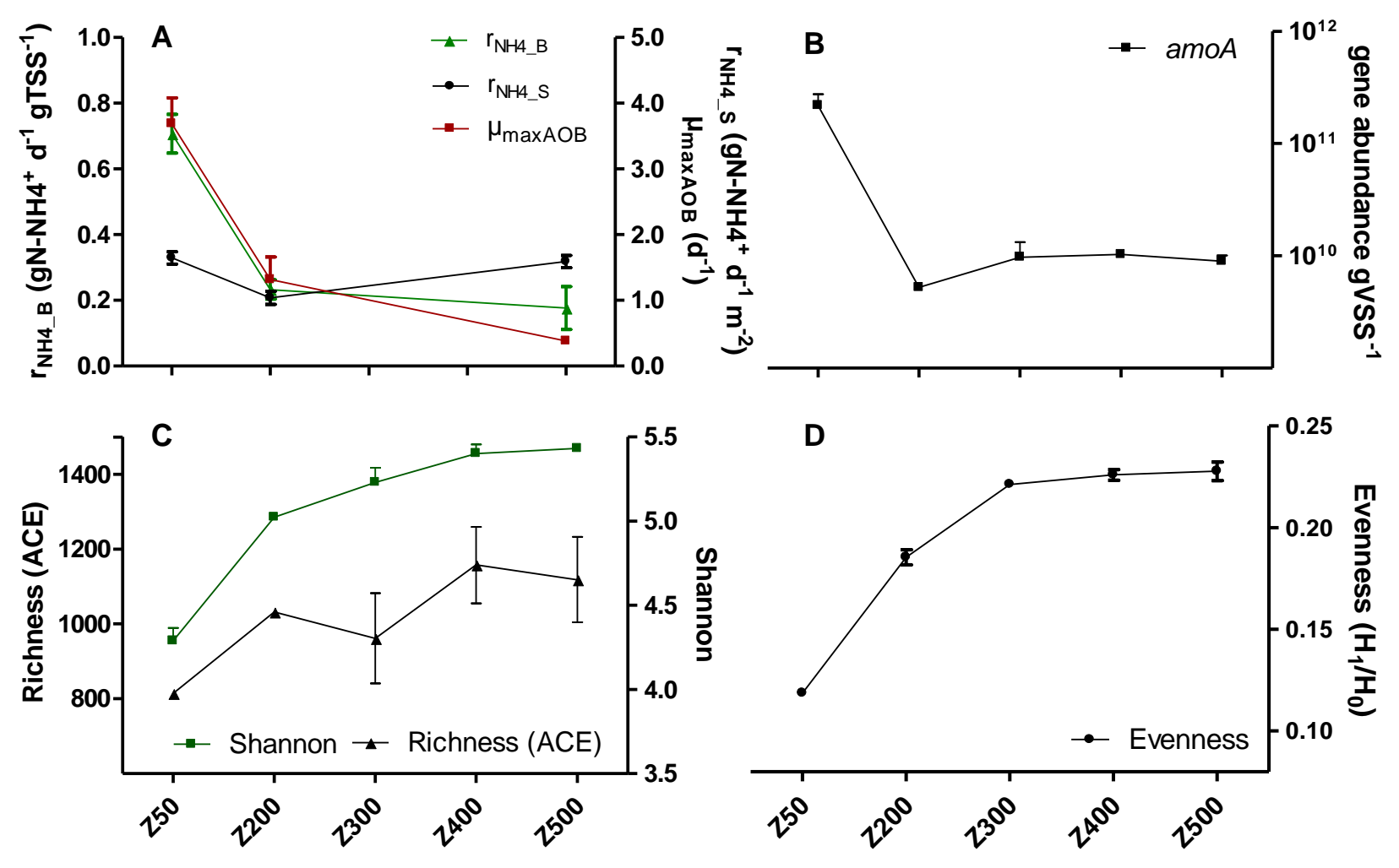

Figure 1. Nitrification rates $\left(\mathrm{r}_{\mathrm{NH} 4 \_\mathrm{B}}\right)$ and specific growth rates of $\mathrm{AOB}\left(\mu_{\operatorname{maxAOB}}\right)$ for $\mathrm{Z50}, \mathrm{Z200}$ and $\mathrm{Z500}$ (A); amoA gene abundance (B); extrapolated taxonomic richness (ACE), Shannon biodiversity (C) and evenness indices (D) estimated for the 5 Z-carriers ( $x$-axis). Errors bars show standard deviation. 

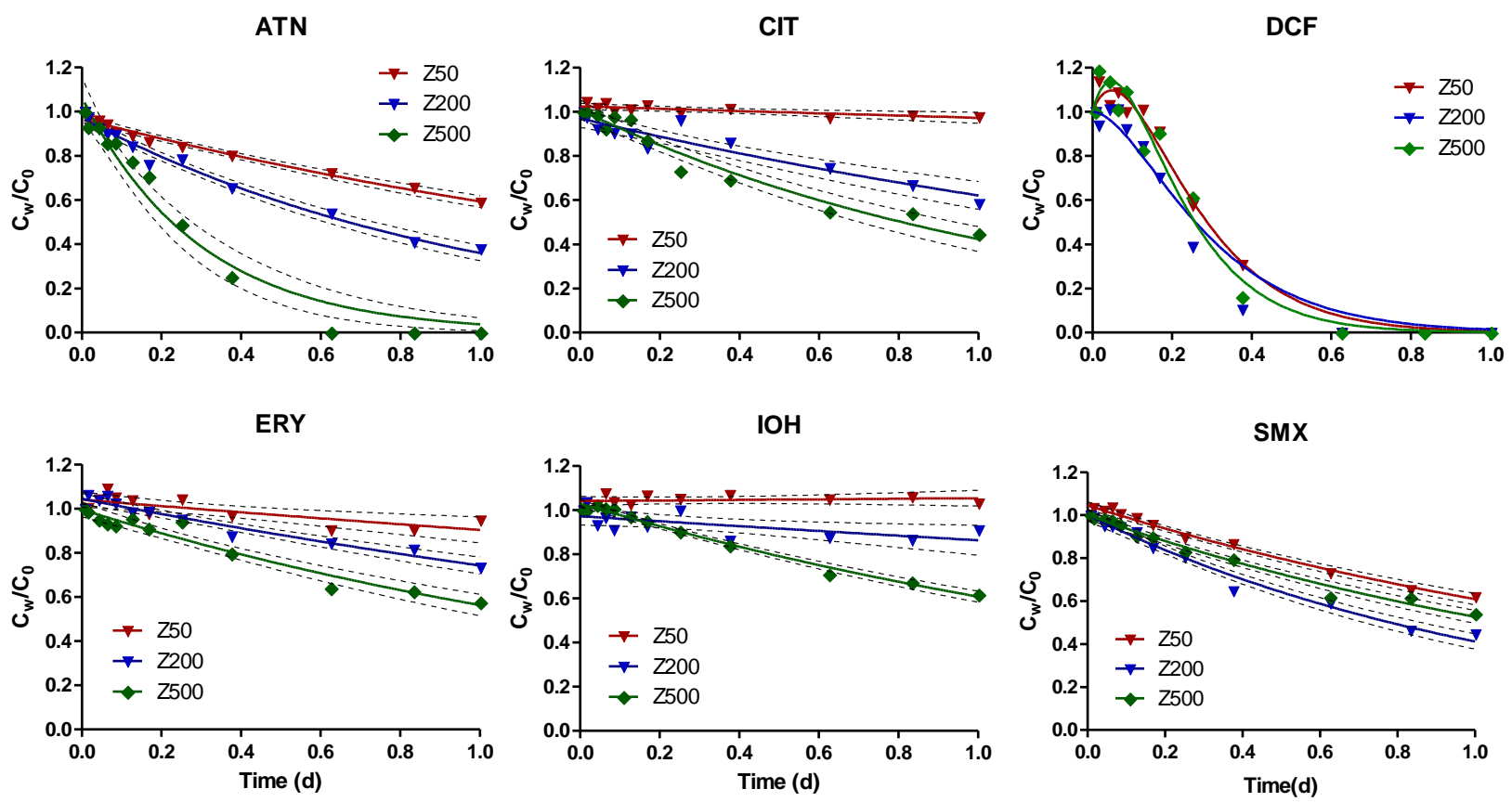

Figure 2. Measured and modelled relative concentration of six representative spiked micropollutants during batch experiment. $C_{w}$ and $C_{0}$ denote the aqueous measured and initial concentration of the spiked chemicals. Dotted lines denote the $95 \%$ confidence interval. 


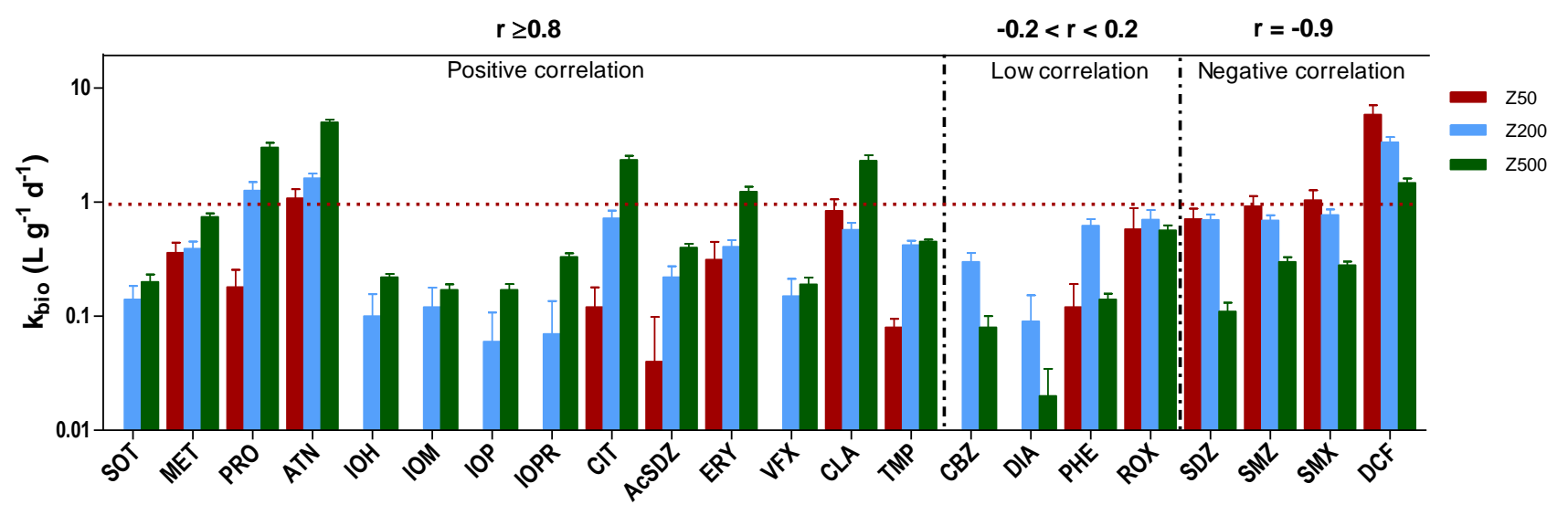

Figure 3. Biotransformation rates $\left(k_{\text {bio }}\right)$ estimated for 22 micropollutants for $3 \mathrm{Z}$-carriers. The fast removal of ibuprofen prevented the estimation of $\mathbf{k}_{\text {bio }}$. Pearson's coefficient $r$ was used to measure the correlation between $k_{b i o}$ and biofilm thickness. 


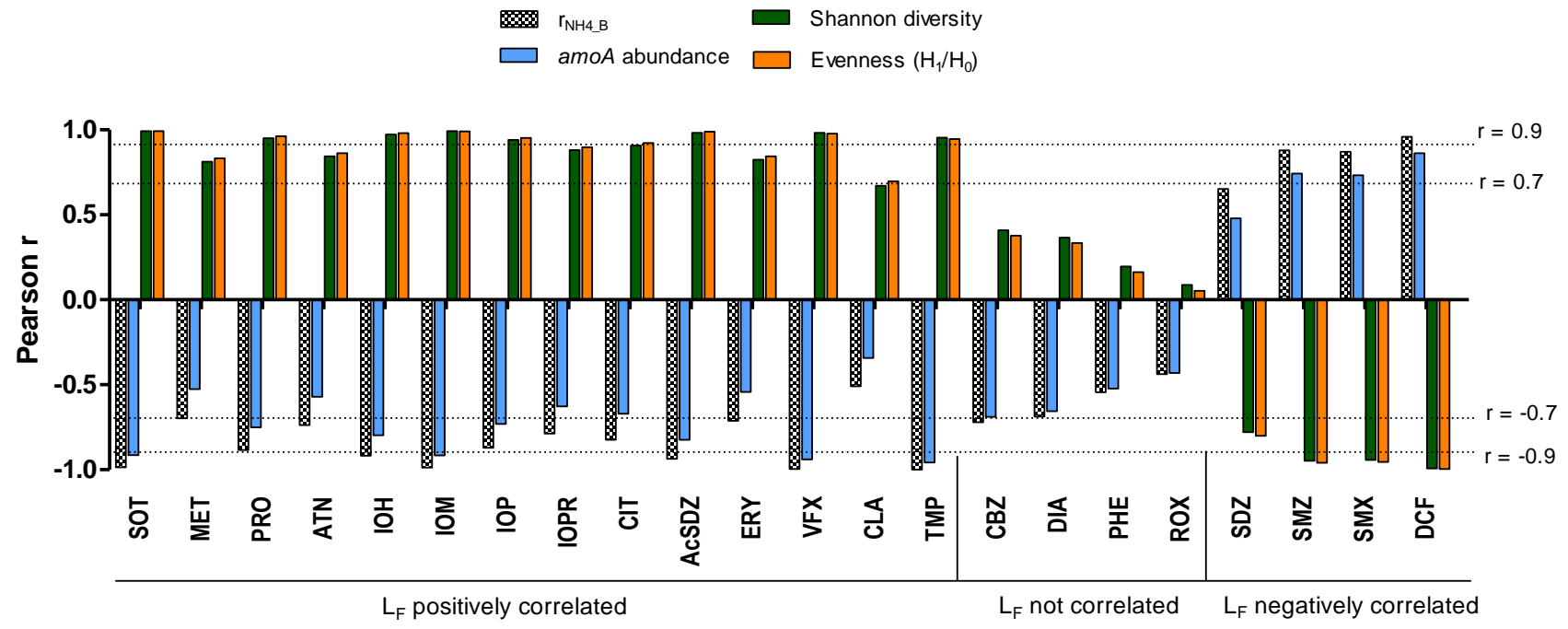

Figure 4. Correlation between estimated biotransformation rate constants $\mathbf{k}_{\text {bio }}$ with nitrification rate $\mathbf{r}_{\mathrm{NH} 4 \_\mathrm{B}}$, amoA abundance, Shannon diversity and evenness indices. $L_{F}$ indicates biofilm thickness. 